\title{
Variações em torno das pesquisas em educação e arte com imagens
}

\author{
Variaciones a cerca de las învestigaciones en educación y arte con \\ imágenes
}

https://doi.org/10.34112/2317-0972a2018v36n72p115-131

Cristian Poletti Mossi ${ }^{1}$

Marilda Oliveira de Oliveira ${ }^{2}$

RESUMO: O artigo trata da produção de pesquisas, sobretudo em educação, que, ao buscar outros parâmetros de produção/validação, se envolvem em alguma medida com arte. Entendendo que as facetas da produção artística são inúmeras e não necessariamente visuais, o recorte mais preciso que foi escolhido para se debruçar é o do uso de materiais visuais em geral nessas investigações. Nesse sentido, após transitar por algumas concepções de arte com as quais os autores têm trabalhado e de discutir sob o ponto de vista teórico a gênese de metodologias artísticas no campo das investigações em educação, uma cena será, ao final do texto, mais especificamente tratada: a da utilização que o autor fez em sua tese de doutorado (orientada pela coautora deste artigo), das imagens de algumas obras da artista visual Shannon Rankin, como disparador visual para constituir o que na pesquisa foi nomeado de 'sobrejustaposições' enquanto estratégia metodológica.

Palavras-chave: Arte; imagem; pesquisa em educação.

RESUMEN: El artigo trata de la producción de estudios, sobretodo en educación, que, al buscar otros equivalentes de producción/validación, se envuelven en alguna medida con arte. Entendiendo que las facetas de la producción artística son inúmeras y no

1. Universidade Federal do Rio Grande do Sul, Porto Alegre, RS, Brasil.

2. Universidade Federal de Santa Maria, Santa Maria, RS, Brasil. 
necesariamente visuales, el recorte más preciso que se elegió para se profundizar es el del uso de materiales visuales en general en esas investigaciones. En ese sentido, después de transitar por algunas concepciones de arte con las cuales los autores han trabajado y de discutir bajo el punto de vista teórico la génesis de metodologías artísticas en el campo de las investigaciones en educación, una escena será, al final del texto, más específicamente tratada: la de la utilización que el autor hizo en su tesis de doctorado (diriiida por la coautora de este artículo), de las imágens de algunas obras de la artista visual Shannon Rankin, como disparador visual para constituir lo que en la investigación fue nombrado de 'sobrejustaposições' como estrategia metodológica.

Palabras Clave: Arte; imagen; investigación en educación.

Arte?

Viviane Mosé, no poema Receita para lavar palavra suja (2004), nos lembra de algo importante para começarmos:

[... a a palavra nela mesma, em si própria, não diz nada. Quem diz é o acordo estabelecido entre quem fala e quem ouve. Quando existe acordo, existe comunicação. Quando o acordo se quebra, ninguém diz mais nada, mesmo usando as mesmas palavras.

Além disso, a escritora, filósofa e psicanalista mencionada nos convida a pensar no quanto as palavras que usamos diariamente estão gastas e repletas de impurezas e que, desse modo, antes de utilizarmos qualquer palavra é importante que a "deixemos de molho", que "a lavemos", observando suas especificidades. Não para que encontremos algum tipo de essência que seria própria das palavras - lembrando que elas em si mesmas são vazias de sentido -, mas porque, segundo a autora, "uma palavra limpa é uma palavra possível”. Assim, uma palavra limpa é uma palavra incorporada.

Dada a complexidade dos infindáveis conceitos para 'arte' e das camadas e camadas de significado incrustadas nessa palavra, resta-nos trabalhar pautados por contingências, apenas. Ao falarmos de pesquisa em arte, com arte, sobre arte, a partir $d a$ arte, dentre tantas outras operações investigativas possíveis em torno do fenômeno que chamamos arte entrelaçado à educação, sobretudo na contemporaneidade, ao menos uma questão nos toma: de que arte falamos? 
Longe de querer sanar a problemática e circunscrevê-la em uma definição única, ou dar a ela uma resposta definitiva e inequívoca, a seguir pontuamos três concepções com as quais temos trabalhado atualmente:

a. A de que arte pode ser, no contraponto de certa concepção que separa certos indivíduos eleitos que a produzem da grande maioria que apenas a consome, aquilo que todo e qualquer indivíduo pode utilizar para transformar, através de técnicas, atitudes, processos e procedimentos específicos, a própria realidade em que está envolvido, produzindo, assim, alguma articulação com o mundo em que se insere, sem necessariamente se preocupar com a legitimação ou institucionalização de um produto que ganharia o status de diferenciação. Se levarmos em conta a etimologia da palavra arte ${ }^{3}$, observaremos que em sua origem grega e latina, respectivamente - a primeira significando técnica (techné) e a segunda significando articulação (ars) -, ambas remetem à tal noção não como uma atividade essencialmente ligada à concepção romântica/moderna de 'obra de arte' (um objeto especial, produzido por um sujeito especial, para ser apreciado pelas pessoas comuns que não produzem arte), mas todo e qualquer fazer que permite ao ser humano se relacionar com o exterior, com a natureza e com ele próprio (parte dessa mesma natureza).

b. A de que arte seria, conforme Deleuze (1981), para além da invenção de formas transcendentais, a captura de forças imanentes. O músico ou alguém que se envolve com música, por exemplo, capturaria - fazendo uso de meios específicos que ele domina - forças inaudíveis, assim como o pintor ou alguém envolvido com pintura (fotografia, desenho, vídeo ou qualquer outra produção imagética) capturaria as forças não visíveis e as apresentaria na condição do que o autor chama de blocos de sensação (perceptos e afectos). Quando Deleuze propõe tal definição, se distancia de certa concepção de artista como ser genial, ou especial, colocando em xeque a possibilidade de que a arte seja a configuração de formas plenamente originais.

É um erro dizer que o pintor está diante de uma superfície branca. A crença figurativa advém deste engano: de fato, se o pintor estivesse diante de uma superfície branca, ela

3. As explanações sobre arte e obra de arte do professor Marcos Ramon (Disponíveis em: <http://www. marcosramon.net/ficcoes/ficcoes-23-a-arte-e-a-obra-de-arte >.) auxiliaram na escrita dessa primeira concepção apresentada. 
poderia reproduzir um objeto exterior que funcionasse como modelo. Mas não é assim. O pintor tem muita coisa na cabeça, ou a sua volta, ou no atelier. Portanto, tudo o que há na sua cabeça ou à sua volta já está na tela, mais ou menos virtualmente, mais ou menos atualmente, antes que ele comece a trabalhar. (DELEUZE, 1981, p. 45).

Assim, junto com a filosofia e a própria ciência, a arte seria uma das três grandes formas de pensamento que teriam como objetivo principal "enfrentar o caos, traçar um plano, esboçar um plano sobre o caos" (DELEUZE; GUATTARI, 1992, p. 253). Não meramente representar o mundo, mas dar acesso ao corpo aquém de sua organização (um Corpo sem Órgãos afetivo) no contato com blocos de sensação. Tal corpo não orgânico - noção que Deleuze (1981) e Deleuze e Guattari (2012a) retomam de Artaud (1983) - não é contra os órgãos (contra o corpo físico), mas contra a organização rígida, autoritária, significante do corpo. No contato com arte, o corpo afetivo - intenso, não extenso - ganha órgãos provisórios, os quais sobrevivem apenas enquanto durar a ação da força (encontro).

c. A de que arte "é uma das maneiras de trabalhar na direção da problematização e da invenção de si e do mundo" (KASTRUP, 2016, p. 4), concorrendo para que se modifique nossa política cognitiva (ainda pautada no esquema platônico da representação), ou seja, a forma como estamos no mundo e entramos em relação com o conhecimento; ou ainda, em suma, nossa forma de cultivo de nós mesmos (KASTRUP, 2009, n. p.). Segundo Kastrup (2016, p. 4), a arte "não é a única estratégia" para que isso seja possível, "mas fornece efetivamente condições para evitar automatismos perceptivos", visto que

A experiência estética pode ser de difícil apreensão, mas, por ter um caráter inquietante, atrai e mesmo obriga a retornar a determinada imagem diversas vezes, interrompendo e voltando, em um vaivém entre o chamado da obra e o desejo de ir além que ela suscita. A experiência estética tem, assim, o potencial de desencadear processos de aprendizagem. (KASTRUP, 2016, p. 4).

Nessa perspectiva, a autora propõe que o conhecimento, no que tange à arte, não é acumulativo nem transmissível, mas que só é possível pensar em ensinar/ aprender arte se entendemos ensino/aprendizagem como compartilhamento 
de experiências, ou melhor, como criar condições para que a experiência (com arte) seja possível.

Dadas essas concepções iniciais, mesmo tendo a certeza de que elas permanecem inconclusas e entendendo que o escopo deste texto não daria conta da extensão da discussão que cada uma delas suscita, de agora em diante transitaremos com a escrita nas imediações da produção de pesquisas, sobretudo em educação, que, ao buscar outros parâmetros e critérios de produção e validação, se envolvem em alguma medida com arte, especialmente naquelas "em que a arte, e os fenômenos dela derivados, seja posicionada em uma centralidade importante, qualquer que seja o seu meio ou o suporte de manifestação e qualquer que seja o seu papel [...]" (OLIVEIRA; CHARREU, 2016, p. 366).

Entendendo que as facetas da produção artística são inúmeras e não necessariamente visuais, o recorte mais preciso que escolhemos para nos debruçar é o do uso de imagens e/ou materiais visuais em geral nessas investigações, ponderando, a partir de Hernández (2013, p. 79), que

[...] diferentes perspectivas e disciplinas consideram, na atualidade, a utilização de imagens na pesquisa em Ciências Sociais e Humanas, configurando, com isso, uma campo de estudos que goza de crescente reconhecimento e interesse.

O autor ainda sugere que "a onipresença das imagens em nossas sociedades", além da "suspeita de que as imagens podem desvendar aquilo que não é possível por outros meios", bem como "a redução de custo e a consequente facilidade de acesso às câmeras fotográficas e de vídeo e aos programas de edição" e o "questionamento, a partir do final dos anos 60 do século passado, do enfoque positivista-realista na investigação sobre [...] as experiências dos seres humanos", são alguns dos fatores que serviram de "[...] reivindicação aos pesquisadores sobre a hora de estudar as imagens existentes ou aquelas que são produzidas no processo de pesquisa (realizadas pelos pesquisadores ou pelos sujeitos participantes)" (HERNÁNDEZ, 2013, p. 79).

Uma cena será, ao final do texto, mais especificamente tratada: a da utilização, feita na tese de doutorado intitulada .um corpo-sem-órgãos, sobrejustaposições. Quem 
a pesquisa [em educação] pensa que é?4, das imagens de algumas obras de Shannon Rankin', como disparador visual para constituir o que na pesquisa nomeamos de 'sobrejustaposições', enquanto estratégia metodológica. A tese buscou operar com imagens (produzidas especialmente para a ocasião, ou oriundas de produções artísticas de outrem) de modo que elas não ilustrassem, ou meramente representassem visualmente o que estava expresso na narrativa escrita, mas que dialogassem com o texto, que o tensionassem (OLIVEIRA; CHARREU, 2016).

\section{INQUIETAÇÕES ACERCA DO QUE TEMOS FEITO COM NÓS MESMOS, OU SOBRE AS PESQUISAS EM EDUCAÇÃO E ARTE COM IMAGENS}

"Como escrever sem nos deixarmos acimentar pelos padrões da escrita acadêmica? Como potencializar a vida e sua capacidade de diferir e criar enquanto pensamos, conversamos, escrevemos, vivemos?” (LINHARES, 2016, p. 7). Essas duas instigantes questões fazem parte do prefácio, de autoria de Célia Linhares, do livro Uma escrita acadêmica outra - ensaios, experiências e invenções (2016), organizado por Cristiana Callai e Anelice Ribetto.

Se, com Larrosa (2016, p. 17), pensarmos que o trabalho na academia "é basicamente um trabalho com palavras", e que o "que fazemos a cada dia é escrever e ler, falar e escutar", nos indagarmos sobre que tipo de escrita temos produzido para dar conta e/ou acompanhar nossos percursos de pesquisa na universidade, sobretudo no campo das Artes e das Humanidades, onde se inserem a Educação e a Arte como áreas de conhecimento, significa também nos indagarmos sobre o que temos feito de nós mesmos nesse espaço.

Temos produzido nossas escritas de modo mais autoritário e prescritivo, como produção inequívoca de verdades inquestionáveis as quais seriam percebidas de modo mais apurado e asséptico por certo olhar cientificista, separado da vida que pulsa? Temos produzido escritas mais abertas, onde os devires inseparáveis das zonas de experiência e produção de pensamento, enfim, do próprio corpo, atravessam

4. Recentemente publicada em forma de livro pela Editora UFSM, com mesmo título, a tese, concluída em 2014 sob orientação da Profa. Dra. Marilda Oliveira de Oliveira, no Programa de Pós-graduação em Educação (Linha de pesquisa Educação e Artes) da Universidade Federal de Santa Maria (UFSM/RS), pode ser acessada na íntegra aqui: <http://repositorio.ufsm.br/bitstream/handle/1/3478/MOSSI\%2C\%2O CRISTIAN\%2oPOLETTI.pdf ? sequence $=1$ \&isAllowed $=\mathrm{y}>$.

5. Para saber mais sobre a artista e seus trabalhos, acesse seu site, disponível em: <http://shannonrankin.com/ home.html>. 
irremediavelmente aquilo que propomos contingencialmente, apenas como um olhar - plural, multifacetado - das infinitas realidades que participamos? Com esses dois questionamentos, não queremos estabelecer um modo melhor e mais correto de escrever e pesquisar, mas, certamente neste texto, nos posicionamos do ponto de vista o qual entende que

Quando escrevemos sem dogmatismos - como quem pesquisa os movimentos contraditórios da vida, abrimos mão da sisudez das certezas que precisariam ser ensinadas, do tom magistral de quem é o dono da verdade, da defesa do que já aprendemos, para colocar-nos dentro e fora do âmbito do já vivido e comprovado e, assim, arrancados dos limites de nós mesmos -, arriscamo-nos a tatear atalhos e caminhos e a balbuciar outras palavras. Então a escrita se faz como uma experiência que nos toma de curiosidade e prazer, expondo-nos ao risco e à aventura de travessias surpreendentes. (LINHARES, 2016, p. 8).

São algumas das inquietações que nos acompanham há algum tempo: como temos nos constituído em meio à nossas pesquisas? Isso, tanto no que concerne aos modos de condução da pesquisa, como aos modos de apresentação da pesquisa, entendendo que pesquisa, pesquisador e objeto pesquisado são inseparáveis. Que outros registros podemos criar para validar nossas investigações, que não sejam necessariamente aqueles que preveem como 'produto' das mesmas a produção de metanarrativas e de metacertezas? Para Larrosa (2016, p. 20-21), chama a atenção um certo cansaço que toma a academia. Cansaço de

[...] ouvir sempre as mesmas coisas ditas no mesmo registro arrogante e monótono, havendo como que uma necessidade de sair desse tédio e uma certa expectativa em relação a qualquer registro de escrita que se apresente como diferente.

Nessa perspectiva, que outras formas de produção, construção, apresentação, validação de nossas pesquisas são possíveis? Por que arriscamos tão pouco? Que torção seria necessária para que outros critérios fossem possíveis? Interessa-nos, nessa medida, retomando as concepções iniciais apresentadas neste artigo, conceber uma investigação em educação que, fazendo uso da potência da arte - mais como postura diante do mundo e da produção de conhecimento e menos como fabricação de um objeto especial -, deslocar aquilo que usualmente chamamos de pesquisa. Algo que confunda e atravesse, em alguma medida, "a distinção entre 
ciência, conhecimento, objetividade e racionalidade, por um lado; e arte, imaginação, subjetividade e irracionalidade, por outro", que cruze e questione tais fronteiras, entendendo a fronteira sempre como "gigantescos mecanismos de exclusão" (LARROSA, 2016, p. 21), pois

[...] o pior que pode acontecer a alguém que tenha pretensões literárias ou poéticas é que lhe digam: 'Isso não é poesia, pode ser qualquer outra coisa, mas não é poesia'; ou, no caso de um pintor: 'Isso não é pintura'. Todos os poetas e pintores que modificaram o que se chama 'poesia' ou o que significa 'pintura' escutaram afirmações como essas. [...] Por isso, são precisamente esses questionamentos de fronteiras que ampliaram o âmbito do visível - ao nos ensinar a olhar de outra maneira o âmbito do pensável, ao nos ensinar a pensar de outro modo - e o âmbito do dizível, ao nos ensinar a falar de outro modo. (LARROSA, 2016, p. 21).

No que concerne ao uso de imagens nas investigações, embora nas duas últimas décadas possam se observar algumas instituições universitárias "mais proeminentes na aceitação e exploração dessas novas metodologias” (OLIVEIRA; CHARREU, 2016, p. 366) que entendem a imagem como parte do escopo argumentativo dos textos de pesquisa e "têm se valido de materiais visuais [...] na constituição de artefatos acadêmicos" (CUNHA, 2015, p. 170), grande parte dos trabalhos ainda são bastante tímidos nesse exercício.

Tal timidez se sobressai sobretudo quando se trata de não operar com as imagens como ilustração ou representação de conteúdos apresentados de forma escrita, mas como potência discursiva que tensiona, amplia, estabelece outras vias de acesso e de vazão ao texto o qual, por sua vez, ao receber imagens que tomam essa outra posição, acaba se tornando também mais poroso, aberto, permeável a outros sentidos e, por sua vez, passível de conexões diversas, as quais podem vir a ser feitas singularmente por cada leitor que se relaciona com ele.

De acordo com Cunha (2015, p. 167):

Nota-se [...] que há uma hierarquização entre as duas linguagens: a escrita porta o 'conhecimento, o saber e a verdade'; e as imagens, muitas vezes, servem para estetizar, expressar sentimentos e, quando muito, como 'prova' de um acontecimento, um registro que 'ilustra', 'comprova' e/ou enaltece a veracidade do que é escrito. 
Isso porque, desde muito cedo aprendemos, ainda na escola, "a privilegiar a palavra em detrimento da imagem", quando nossos professores e nossas professoras, por exemplo, escrevem ao lado dos desenhos que produzimos aquilo que o mesmo significa. Ou seja, aprendemos que "a imagem deve corresponder ao mundo cognoscível" (CUNHA, 2015, p. 168).

Isso posto, tem nos interessado buscar modos de incorporar as imagens nas investigações, de acordo com Mossi (2017, p. 187-188):

I. Como "blocos de naturezas diversas" das palavras, ou seja, nem como opostas diretas, nem como sinônimas, mas como "entes [...] que podem ou não ser com elas friccionados, flechados, atravessados, gerando fluxos incertos";

II. Entendendo que "não há de haver uma só palavra que faça caber em si os efeitos das paixões provenientes das imagens", bem como "não há de haver uma só imagem que consiga envolver tudo o que podem as palavras";

III. Considerando que "imagens são corpos que se estendem, em sua superfície, a constelações de sentidos e significados" e que "coagem o pensamento a pensar", fazendo assim, referência também a Deleuze (2006);

IV. Enquanto superfícies que nada escondem, nada disfarçam, nada camuflam e, portanto, nada está para ser lido, desvelado, decodificado, visto que na profundeza de sua espessura sem volume "encontra-se apenas um murmúrio indefinido, um gemido resultante das relações, das ações e paixões entre seus elementos infinitesimais constituintes";

V. Incorporando-as junto ao texto e aos percursos de pesquisa como "arsenais, substâncias de experimentação, e não códigos de interpretação";

VI. Ponderando que o que mais interessa a respeito delas, não é nem o que/quem as gerou (sua origem), nem o que se pode dizer delas em última instância (como se fosse possível circunscrever sentidos e significados que elas conteriam em si), mas considerando que "estão sempre no meio, não têm ponto de chegada nem de partida, nem origem nem finalidade fixas", elas estão sempre em mutação, sempre em processo, sempre produzindo ressonâncias em quem as visualiza e faz uso delas.

Assim, uma das problemáticas que tem nos tomado é de que modos as imagens podem ser utilizadas como potências para que outros modos de pesquisar em educação sejam possíveis? Ou seja, compreendendo que as imagens podem nos ajudar a formular problemáticas, a conceber métodos, a articular procedimentos, a construir 
argumentos, a operar com dados produzidos, dentre outras ações, entendemos, junto com Deleuze e Guattari (2012b), que podem também colocar nosso pensamento em funcionamento maquínico ${ }^{6}$, precipitando as estratificações duras que envolvem programas investigativos "acimentados", retomando a expressão de Linhares (2016) mencionada anteriormente.

\section{INVESTIGAR COM ARTE OU UMA CRIAÇÃO METODOLÓGICA EM SOBREJUSTAPOSIÇÕES}

Oliveira e Charreu (2016, p. 371-372) afirmam que, "desde os anos 70 e 80 na América do Norte alguns pesquisadores vêm fazendo tentativas de explorar uma outra forma de pensar metodologicamente as pesquisas educacionais", dando início a diversas "metodologias artísticas" ou "investigações baseadas nas artes" as quais surgem mediante "um desajuste entre aquilo que se produz e a tentativa de enquadrá-lo em metodologias científicas”.

Desse modo, compreende-se que se está trabalhando com uma metodologia artística, sempre que utilizamos na investigação

[...] procedimentos artísticos, sejam estes literários, cênicos, visuais ou performativos, para dar conta de práticas de experiências nas que tanto os diferentes sujeitos (pesquisador, leitor, colaborador) como as interpretações sobre suas experiências revelem aspectos que não são visíveis em outro tipo de investigação. (OLIVEIRA; CHARREU, 2016, p. 372).

Se nos reportarmos novamente às concepções sobre arte expostas na primeira seção deste texto, podemos pensar em investigações com arte $^{7}$ as quais, em primeiro lugar, operam levando em conta mais uma postura artística incorporada pelo pesquisador do que um fazer especial executado por um ser especial (o artista), seja do ponto de vista da criação de métodos e procedimentos investigativos, seja do ponto de vista das análises e dos arranjos (tanto conceituais, como formais/ materiais/visuais/performativos) que se estabelecem com os dados gerados pela/ na investigação; em segundo lugar, compreendem a arte como uma forma, dentre

6. “(...) uma máquina é como um conjunto de pontas que se inserem no agenciamento em vias de desterritorialização, para traçar suas variações e mutações” (DELEUZE; GUATTARI, 2012b, p. 154).

7. Não necessariamente em arte, já que podem estar circunscritas em outras áreas de saber e operar com arte e/ou incorporar uma postura artística no que concerne a seus métodos, procedimentos e análises. 
tantas, de sistematizar o conhecimento já produzido e também de conceber novos saberes fazendo uso, talvez, de recursos não usuais como imagens, sons, poesia, movimentos corporais, materiais inusitados, dentre outros, de forma a dizer, ver, ouvir, expor, ler o que outros disseram, viram, ouviram, expuseram, leram, mas que, ainda assim, permanece oculto (OLIVEIRA; CHARREU, 2016), não foi dito, visto, ouvido, exposto, lido do mesmo jeito; em terceiro lugar, suspendem os modos já instaurados de se relacionar com o conhecimento, com o mundo, com nós mesmos (retomando a fala de Kastrup citada anteriormente), propondo outras maneiras de investigar, menos colados em representar o mundo e mais engajados em criar mundos possíveis, menos coladas em acumular saberes e mais engajadas em compartilhar experiências.

Assim, de modo a finalizar o texto, gostaríamos de, conforme anunciado no início, fazer uma breve explanação acerca da criação metodológica que se deu na tese .um corpo-sem-órgãos, sobrejustaposições. Quem a pesquisa [em educação] pensa que é?, a qual utilizou como um dos disparadores visuais para pensar seus percursos metodológicos algumas imagens de obras da artista visual Shannon Rankin.

Vale dizer que a referida tese teve como objetivo operar com a prática do corpo-sem-órgãos, que Deleuze e Guattari (2012a) resgatam de Artaud (1947), para pensar a produção de uma pesquisa em educação que se deu entre arte e filosofia. Em linhas gerais, quando Artaud formula tal noção vinculada à sua prática dramatúrgica, enuncia que a grande doença do homem são seus órgãos, ou seja, certa constituição prévia, endurecida, a qual o corpo receberia antes mesmo de nascer e que o engessaria no que concerne às múltiplas potências que ele poderia alcançar não fossem tais prescrições. Bem, podemos dizer que a proposta que atravessa toda a produção filosófica de Deleuze em parceria com Guattari é justamente escapar de formas pré-datadas e pré-formuladas de guiar o pensamento, inseparável do corpo, criando modos de que o mesmo se abra para um impensável, para devires onde não se façam mais possíveis organizações identitárias/subjetivas/significantes fixas. Nesse sentido, para os autores, fabricar um Corpo sem Órgãos se trata de um exercício que não se acaba nunca de fazer, e que se projeta mais contra o organismo do que contra os órgãos (DELEUZE; GUATTARI, 2012a).

Nesse sentido, uma hipótese foi formulada: a de que há uma Pesquisa Majoritária em Educação, ainda ligada a certo paradigma oriundo das pesquisas naturais e exatas, para as quais seria possível, através do olhar apurado do investigador - sempre apartado do objeto investigado e de um lugar de autoridade do saber-, diagnosticar 
realidades e oferecer soluções, excluindo o máximo possível de variantes e singularidades e seguindo sempre uma imagem dogmática do pensamento (DELEUZE, 2006) e do conhecimento. Em meio a essa Grande Pesquisa, uma pesquisa menor, uma pesquisa-sem-órgãos que não reconhece organismos prévios, poderia se instalar "como uma gagueira a qual atravessa a Língua-Mãe das pesquisas" (MOSSI, 2017, p. 53) e "que trata de produzir um respiro nas pesquisas em educação majoritárias" (MOSSI, 2017, p. 54).

Tal pesquisa menor viria a se constituir, portanto, através de sobrejustaposições afetivas de elementos/encontros que deflagraram o pensamento a pensar com/ sobre/em pesquisa. A palavra contraída sobrejustaposições se trata de uma noção trabalhada há alguns anos por nós, resultante das palavras sobreposição, justaposição e posição, na ocasião da escrita da dissertação de mestrado (MOSSI, 2010), e já amplamente mapeada em outras publicações, como, por exemplo, em Mossi (2015; 2017) para citar publicações mais recentes.

Trata-se de conceber uma pesquisa que se constitua por camadas de imagens e de escritos, especialmente, embora não exclua outras materialidades, os quais sejam arranjados ora sobrepostos, ora justapostos e que, a cada vez, instituam posições provisórias do pesquisador em torno das variações possíveis que são deflagradas de acordo com as conexões que vão sendo traçadas entre os elementos. Nas sobrejustaposições não há nunca uma totalidade perdida que seria alcançada em algum momento, mas sempre novas possibilidades de arranjo que vão sendo possíveis, tensionando palavras e imagens, palavras e palavras, imagens e imagens.

Nesse ponto, podemos dizer que as sobrejustaposições dialogam com o conceito de multiplicidade em Deleuze e Guattari (2011), não como múltiplo oposto ao uno, mas sempre como multiplicidade de multiplicidades a $n$ dimensões e, claro, também com a noção de mapa que, para Deleuze e Guattari (2011, p. 30), se define por um arranjo sempre "aberto, conectável em todas as suas dimensões, desmontável, reversível, suscetível de receber modificações constantemente”.

No que concerne ao uso das imagens das obras de Shannon Rankin na pesquisa (dados seus objetivos expressos acima), como por exemplo Germinate (2008) e Charted (2010), dentre outras, é claro, podemos dizer que o que nos chama a atenção é o modo como a artista

[...] subverte mapas já instituídos e legitimados - recorta-os, cola-os em diversos formatos na parede, amassa-os, dobra-os - e, com o auxílio de alfinetes e linhas de 
desenho, cria conexões individuais para tais composições, colocando assim em xeque o que conhecemos como escrita de uma geografia física e política oficializada. (MOSSI, 2017, p. 101).

Nesse sentido, é como se a artista, no plano das materialidades que utiliza para construir sua obra, interviesse em uma imagem dogmática do pensamento já instituída, tal como o que buscamos fazer na tese no tocante às Pesquisas em Educação ditas Majoritárias, porém fazendo uso de materialidades conceituais/imagéticas/ teóricas/textuais. Não que as obras de Rankin ilustrem ou representem nossa ação de pesquisa, mas, ao contrário, elas nos ajudam a pensar em caminhos e ações plausíveis, oferecem-nos um instrumental para que o arranjo da pesquisa seja possível. As sobrejustaposições de Rankin são também as nossas, na medida em que ela

[...] liga pontos, inventa regiões de tensão, cria espaços, aberturas e formatos inesperados. Há em suas peças toda uma poética [...] do que [...] chamamos de sobrejustaposição: imantação e repulsão de elementos [...]. (MOSSI, 2017, p. 101).

Ela cria tensões no plano utilizando operações simples como dobrar, cortar, furar, riscar, ligar. Os mapas onde interfere já estão prontos, mas ela faz aparecer neles outros possíveis significados fazendo uso de vetores e forças diferenciais que passam a interferir nas cartografias

[...] através de rasgos, recortes, colagens, produção de camadas e ritmos, conjunção e atravessamento de pontos, demarcação de encontros e repulsões entre elementos, abertura a espaços fendidos, não preenchidos. Tudo isso em um plano sem lugares fixos, preestabelecidos. (MOSSI, 2017, p. 102).

A artista traça experimentações com os mapas, abrindo mão desses artefatos como imagens/textos passíveis de interpretação. Ela recria para eles seu uso, dando a eles outras posições não condicionadas a guiar possíveis caminhos, estabelecer localizações e direções.

Em certos trabalhos [...], Rankin varia a concentração de alfinetes e de elementos em algumas partes do plano, ou seja, em alguns locais os alfinetes apresentam-se mais agrupados (como se sofressem uma imantação misteriosa) e em outros mais afastados, 
deixando espaço para que o fundo branco, o vazio, o nada, o espaço liso seja incorporado e potencializado visualmente na obra, de modo a criar dimensões e profundidades bastante intrigantes. (MOSSI, 2017, p. 102).

Desse modo, é como se a artista deixasse sempre algo inconcluso, sempre uma potência de reconfiguração em aberto, sempre a possibilidade de que outros elementos possam passar a fazer parte dos conjuntos apresentados.

Seus trabalhos dialogam com a tese na medida que, no que concerne à sua metodologia de construção, que se deu baseada especialmente no arranjo e experimentação com textos e imagens, essa última também buscou operar com a distribuição (sobrejustaposição) de elementos sobre um plano, criando em alguns momentos mais tensionamento entre os mesmos e, em outros, deixando espaços em aberto para que outras reconfigurações fossem possíveis.

Não se trata de mera ilusão perspectivista condicionada a primeiros, segundos, terceiros planos, mas de sinuosos tensores que demarcam entremeios, espaços, vias, dobramentos, entradas e fazem assim a superfície delirar por sobrejustaposições. (MOSSI, 2017, p. 102-103).

Não se trata de escrever uma pesquisa querendo dar conta de uma realidade apartada do texto, como se ele pudesse ser um retrato realista do material empírico investigado, mas de fazer da própria escrita o laboratório investigativo, na medida que, enquanto é produzido, atravessado por imagens, precipita seu objeto - que nunca se mantém o mesmo -, gera perguntas, convoca leitores e deflagra pensamento. É em si mesmo vida, corpo que pulsa, cicatriz.

\section{REFERÊNCIAS}

ARTAUD, Antonin. Para acabar com o julgamento de Deus (1947). In: WILLER, Claudio (Tradução, seleção e notas). Escritos de Antonin Artaud. Porto Alegre: L\&PM, 1983.

CALLAI, Cristiana; RIBETTO, Anelice (Org.). Uma escrita acadêmica outra: ensaios, experiências e invenções. Rio de Janeiro: Lamparina, 2016.

CUNHA, Susana Rangel Vieira da. Materiais visuais na pesquisa em educação. In: MARTINS, Raimundo; TOURINHO, Irene (Org.). Educação da cultura visual: aprender... pesquisar... ensinar... Santa Maria: Ed. da UFSM, 2015. p. 167-190. 
DELEUZE, Gilles. Diferença e repetição. Tradução de Luiz Orlandi e Roberto Machado. 2. ed. Rio de Janeiro: Graal, 2006.

. Francis Bacon: logique de la sensation. Paris: Aux Éditions de la Différence, 1981. Tradução de Silvio Ferraz e Annita Costa Malufe, sem revisão. Disponível em: <http:// conexoesclinicas.com.br/wp-content/uploads/2015/12/deleuze-francis-bacon-logica-dasensacao-1.pdf $>$. Acesso em: mar. 2017.

DELEUZE, Gilles; GUATTARI, Félix. Mil platôs: capitalismo e esquizofrenia, vol. 1. 2. ed. Tradução de Ana Lúcia de Oliveira Aurélio Guerra e Célia Pinto Costa. Rio de Janeiro: Ed. 34, 2011.

. Mil platôs: capitalismo e esquizofrenia, vol. 2. 2. ed. Tradução de Aurélio Guerra Neto, Ana Lúcia de Oliveira, Lúcia Cláudia Leão e Suely Rolnik. São Paulo: Ed. 34, $2012 a$.

. Mil platôs: capitalismo e esquizofrenia, vol. 4. 2. ed. Tradução de Suely Rolnik. São Paulo: Ed. 34, 2012b.

. O que é a filosofia? Tradução de Bento Jr. e Alberto Alonso Muñoz. Rio de Janeiro: Ed. 34, 1992.

HERNÁNDEZ, Fernando. Pesquisar com imagens, pesquisa sobre imagens: revelar aquilo que permanece invisível nas pedagogias da cultura visual. In: MARTINS, Raimundo; TOURINHO, Irene (Org.). Processos e práticas de pesquisa em cultura visual e educação. Santa Maria: Editora da UFSM, 2013. p. 77-95.

KASTRUP, Virgínia. Educação e invenção em tempos de incerteza. In: VOLZ, Jochen; PRATES, Valquiria (Org.). Incerteza viva: processos artísticos e pedagógicos $-32^{\mathrm{a}}$ Bienal de São Paulo. São Paulo: Fundação Bienal de São Paulo, 2016. p. 1-5.

. A aprendizagem inventiva - entrevista, 2009. Disponível em: <https://www.youtube.com/ watch?v=Sz7-cLdgsVk>. Acesso em: 25 ago. 2017

LARROSA, Jorge. O ensaio e a escrita acadêmica. In: CALLAI, Cristiana; RIBETTO, Anelice (Org.). Uma escrita acadêmica outra: ensaios, experiências e invenções. Rio de Janeiro: Lamparina, 2016. p. 17-30.

LINHARES, Célia. Escrever e viver: estranhamentos e entranhamentos recíprocos. In: CALLAI, Cristiana; RIBETTO, Anelice (Org.). Uma escrita acadêmica outra: ensaios, experiências e invenções. Rio de Janeiro: Lamparina, 2016. p. 7-11.

MOSÉ, Viviane. Receita para lavar palavra suja. In: ___ Receita para lavar palavra suja. Rio de Janeiro: Arteclara, 2004. Disponível em: <https://www.youtube.com/ watch?v=QslBxWXR6ZQ $>$. Acesso em: 25 ago. 2017

MOSSI, Cristian Poletti. .um corpo-sem-órgãos, sobrejustaposições. Quem a pesquisa [em educação] pensa que é?. 2014. 124 f. Tese (Doutorado em Educação)- Universidade Federal de Santa Maria, Santa Maria, RS, 2014.

. Um Corpo-sem-Órgãos, Sobrejustaposições - Quem a pesquisa [em educação] pensa que é? Santa Maria/RS: Editora da UFSM, 2017.

. Uma pesquisa-sem-órgãos: imagens, escritas, sobrejustaposições... In: Anais do $24^{\circ}$ Encontro Nacional da Associação de Pesquisadores em Artes Plásticas (ANPAP): Compartilhamentos na arte: redes e conexões, Santa Maria/RS, p.3353-3367, 2015. Disponível 
em: <http://anpap.org.br/anais/2015/simposios/s8/cristian_poletti_mossi.pdf >. Acesso em: 21 ago. 2017.

. Possíveis territorialidades e a produção crítica da arte suturas e sobrejustaposições entre vestes sem corpos e corpos sem vestes. 2010. 80 f. Dissertação (Mestrado em Artes)- Universidade Federal de Santa Maria, Santa Maria, RS, 2010.

OLIVEIRA, Marilda Oliveira de; CHARREU, Leonardo Augusto. Contribuições da perspectiva metodológica "Investigação baseada nas artes" e da a/r/tografia para as pesquisas em educação. Educação em Revista. Belo Horizonte, v. 32, n. 1, p. 365-382, Mar. 2016. Disponível em: <http:// www.scielo.br/scielo.php?script=sci_arttext\&pid=So102-46982016000100365\&lng=en\&nrm=i so>. Acesso em: 04 set. 2017. http://dx.doi.org/10.1590/o102-4698140547.

RAMON, Marcos. Fiç̧ões \#23 - A arte e a obra de arte. Disponível em <http://www.marcosramon. net/ficcoes/ficcoes-23-a-arte-e-a-obra-de-arte> Acesso em: 25 ago. 2017.

\section{SOBRE OS AUTORES}

Cristian Poletti Mossi é graduado em Desenho e Plástica - Bacharelado e Licenciatura, tem Mestrado em Artes Visuais - Área de concentração Arte Contemporânea e Doutorado em Educação - Linha de Pesquisa Educação e Artes (todos pela Universidade Federal de Santa Maria). É professor/pesquisador da Universidade Federal do Rio Grande do Sul. Tem experiência na área de formação de professores em artes visuais, com pesquisa nos seguintes temas: criação, docência, leitura/escrita com imagens, na interface com as filosofias da diferença. É membro pesquisador do GEPAEC - Grupo de Estudos e Pesquisas em Arte, Educação e Cultura e do ARTEVERSA - Grupo de Estudo e Pesquisa em Arte e Docência. E-mail: cristianmossi@gmail.com.

Marilda Oliveira de Oliveira é graduada em Artes Plásticas - Bacharelado em Cerâmica e Licenciatura Plena (Universidade Federal de Santa Maria), tem Mestrado em Antropologia Social e Doutorado em História da Arte (ambos pela Universidade de Barcelona, Espanha). É professora associada IV do Departamento de Metodologia da Universidade Federal de Santa Maria. Pesquisadora do Programa de Pós-Graduação em Educação, na linha de pesquisa - Educação e Artes, onde orienta dissertações e teses. Tem experiência na área de formação de professores de artes visuais, com pesquisa nos seguintes temas: docência, leitura e escrita com as filosofias da diferença. Coordena o GEPAEC 
- Grupo de Estudos e Pesquisas em Arte, Educação e Cultura (CNPQ/UFSM) e é Editora Chefe da Revista Digital do Laboratório de Artes Visuais, UFSM. E-mail: marildaoliveira27@gmail.com.

Recebido em 04 de setembro de 2017 e aprovado em 15 de outubro de 2017. 